\title{
LA DEMOCRACIA DEL LIBRE MERCADO. LA INTERVENCIÓN PATRONAL EN EL SISTEMA POLÍTICO DE LA TRANSICIÓN
}

\section{A laissez-faire democracy. Employers' intervention in the political system of the Spanish transition}

\author{
GUILLERMO GARCÍA CRESPO \\ Centro de Estudios sobre Dictaduras y Democracias (CEDID) \\ Universidad Autónoma de Barcelona \\ guillermo.garcia.crespo@gmail.com
}

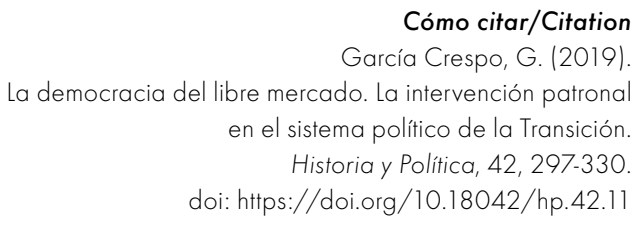

(Recepción: 10/10/2018; evaluación: 27/12/2018; aceptación: 05/04/2019; publicación: 13/12/2019)

\section{Resumen}

Este artículo analiza la intervención de las principales organizaciones empresariales españolas, la CEOE y Fomento del Trabajo, en el sistema político de la Transición. El esquema propuesto parte del contexto económico - final de los Treinta Gloriosos y auge del neoliberalismo-y político - contrarrevolución conservadora- de la década de los setenta en Occidente para estudiar los fundamentos ideológicos que impulsaron al patronato espańol a inmiscuirse en la financiación irregular de los partidos y a poner en marcha un amplio dispositivo de carácter reservado con el fin de orientar el voto hacia las formaciones de centro derecha. Para conocer las características de la estructura reticular creada para influir sobre el voto en el ciclo electoral 1980-1982, así como la responsabilidad de los grupos de presión económicos en la crisis del partido gubernamental, la UCD, me he 
servido de una documentación hasta ahora inédita: el fondo personal de Carlos Ferrer Salat, primer presidente de la CEOE.

\title{
Palabras clave
}

CEOE; Transición; neoliberalismo; organizaciones patronales; grupos de presión económicos.

\begin{abstract}
This article examines the intervention of the main Spanish business organizations, the Spanish Confederation of Employers' Organizations (CEOE) and Fomento del Trabajo, in the political system of the Transition. The proposed outline begins with both the economic context - the end of the Thirty Glorious Years and boom of neoliberalism - and the political context — conservative counterrevolution- of the 70's in the West, in order to study the ideological foundations that led Spanish organizations to interfere with the irregular financing of political parties and launching an underground scheme a covert plan to influence the vote towards the centre-right parties. To understand the characteristics of the network structure created to influence the vote in the electoral cycle of 1980-1982, as well as the responsibility of economic pressure groups in the crisis of the Governing party, the Union of the Democratic Centre (UCD), I have used some previously unpublished documentation: the personal records of Carlos Ferrer Salat, first president of the CEOE. In light of the objectives and results of this strategy, the article evaluates the success of an intervention that raises some doubts about its possible incompatibility with the principles of representativeness, participation, and transparency on which liberal democracies are built.
\end{abstract}

\section{Keywords}

CEOE; Spanish transition to democracy; neoliberalism; business organizations; economic pressure groups. 
I. INTRODUCCIÓN. II. LOS AÑOS CRÍTICOS: EL DESAFÍO AL ORDEN CAPITALISTA Y LA CONTRARREVOLUCIÓN CONSERVADORA. III. EL «APOLITICISMO»PATRONAL. IV. PATROCINANDO LA «MAYORÍA NATURAL». V. LA «FÓRMULA MOLINAS». VI. LOS GRUPOS OPERATIVOS REGIONALES. VII. CONCLUSIONES. BIBLIOGRAFíA.

\section{INTRODUCCIÓN}

Este artículo plantea una aproximación a los fundamentos ideológicos de la intervención empresarial en el sistema político de la Transición, una intervención directa que, como señaló Salvador Aguilar, no "tenía precedentes en sociedades de nuestro entorno", y que convirtió parcialmente a la organización-cúpula CEOE en «un elemento más del sistema político». Para ello, me centraré en la participación de las organizaciones representativas del empresariado español (la citada CEOE) y catalán (Fomento del Trabajo) en la financiación de los partidos y en las campańas electorales del ciclo 1980-1982, a partir del análisis de documentación inédita procedente del archivo personal del que fuera presidente de ambas organizaciones, Carlos Ferrer Salat².

Desde un plano teórico, este trabajo aborda un tema ampliamente estudiado por diferentes disciplinas de las ciencias sociales: la influencia que ejercen los grupos de interés económicos sobre la clase política y los procesos de toma de decisiones públicas en el orden institucional de los estados liberaldemocráticos. La acción empresarial organizada ocupa un papel destacado en las construcciones teóricas que han dominado los estudios en este ámbito. A efectos de este trabajo, resulta de indudable interés la discusión historiográfica sobre las características de la interacción entre empresarios y políticos o, para ser más precisos, los vínculos orgánicos entre ambas esferas y el posible dominio que ejercerían unos actores sobre los otros.

Aguilar (1985a): 204.

2 El fondo se encuentra en fase de inventario, razón por la cual los números de referencia que se aportan son provisionales. El presente artículo ha sido posible gracias a la colaboración de la familia de Carlos Ferrer Salat, que me ha permitido la consulta de sus archivos. También quiero expresar mi agradecimiento a Fabián Márquez, cuyo testimonio ha sido de gran ayuda. 
Desde una mirada retrospectiva, Mercedes Cabrera y Fernando del Rey lamentaban la existencia de "una visión genérica del pasado», condicionada por una coyuntura política — la Espańa franquista—, «donde se hizo recaer sobre las oligarquías los males culpables de lastrar el progreso y la democratización del país en los últimos doscientos años»" Para estos autores, ni en el retraso económico secular que parece aquejar a España ni en su evolución política durante el siglo xx, el papel del hombre de negocios puede considerarse relevante: los empresarios fueron «unos actores entre otros, ni siquiera determinantes como tales empresarios, porque no tuvieron fuerza para ello» ${ }^{4}$, afirmación que, a juicio de Manuel Pérez Ledesma, resultaba tan «provocadora como todavía no demostrada ${ }^{5}$. Esta cualidad de la clase empresarial no impidió a Cabrera y Rey reconocer, respecto de la dictadura franquista, que «pese al importante margen de independencia con que la clase política pudiera diseñar sus proyectos, no cabe duda de que nunca hasta entonces había existido una vinculación tan fuerte entre las instituciones del Estado y los intereses económicos» ${ }^{6}$. También parece constatada la existencia de gestiones a título individual por parte de empresarios bien conectados con las estructuras del poder franquista. Una realidad que ha sido confirmada por Pilar Toboso al constatar que "durante la dictadura se configuró un grupo empresarial significativo que si bien no contó con una asociación profesional, sí consiguió por medios extraoficiales el apoyo de las autoridades para el desarrollo de sus negocios», aun reconociendo la dificultad de establecer estos vínculos, pues con frecuencia se realizaban por «cauces informales»?

En opinión de Mercedes Cabrera, la «relativa incapacidad» de la patronal CEOE «para influir en las decisiones de la política económica» habría abonado el terreno a una intervención directa en los procesos electorales del período 1980-82 y a apoyar la creación de una "gran derecha» política, «un factor más - no el único, ni probablemente el decisivo- en la descomposición» del partido gubernamental ${ }^{8}$. Asumiendo que el empresariado español, en su calidad de grupo de interés, no ejerció «un papel protagonista en el proceso transicional», Ángeles González observa que el repertorio de acciones de la patronal sobre el Gobierno, los partidos o la opinión pública abarcó desde la persuasión a la intimidación, al tiempo que los empresarios «contribuyeron a

\footnotetext{
Cabrera y Rey Reguillo (2002): 329.

Cabrera (1997): 274.

Pérez Ledesma (1997): 292.

Cabrera y Rey Reguillo (1997): 27.

7 Toboso (2007): 145.

8 Cabrera (2003). 51-62.
} 
determinar qué tipo de democracia habría de configurarse y, desde esa perspectiva, coadyuvaron a su legitimación y consolidación»".

Salvador Aguilar matiza el rol desempeñado por la organización patronal en la consolidación del sistema democrático, que respalda a partir de una "visión puramente instrumental del mismo». Además, cuando se desciende a las bases empresariales, que "perciben la realidad en términos exclusivamente de su propia empresa y a corto plazo», es fácil percibir actitudes que reflejan desconfianza hacia la práctica democrática, que es interpretada como una «imposición ajena y como una especie de gasto fijo de representación de carácter superfluo $»^{10}$.

La tesis de la primacía de la política ya había sido avanzada por Juan J. Linz al atestiguar que «entre las características distintivas de la política de intereses en España, quizá una de las más destacables sea que la política tiene precedencia sobre los intereses». No obstante, para este ilustre sociólogo y pionero en el estudio del empresariado espańol, esto no significaría "que grupos de intereses, económicos y sociales, no ejerzan una influencia decisiva en el proceso de formación de políticas (policies), sino que su institucionalización y legitimación tiene menos éxito que en otros países»" ${ }^{11}$. Por su parte, Víctor Pérez Díaz ha introducido la noción de «instrumentalización recíproca» para caracterizar las relaciones entre clase empresarial y clase política en las sociedades liberales ${ }^{12}$.

Frente a la crítica de la instrumentalización, otros autores han defendido la existencia en España de una alianza entre miembros de la burguesía financiera y empresarial junto a otros representantes de los grupos sociales dominantes (políticos, aristócratas, militares y jerarquía eclesiástica) que se sirve de las estructuras del Estado para ejercer el poder y la hegemonía en el cuerpo social. Pioneros de este paradigma fueron los estudios sobre "la trama del tejido social de las élites» y conceptos como el del «bloque de poder» de uno de los historiadores españoles más influyentes del siglo xx, Manuel Tuñón de Lara, a partir de una metodología multidisciplinar que adaptaba los modelos teóricos de las ciencias sociales y un enfoque de raigambre marxista ${ }^{13}$.

Con relación al estudio de las élites, Juan Pro nos previene contra la postergación de los «solapamientos significativos» entre la clase política y la empresarial: «Los vínculos entre políticos y empresarios son muchas veces

\footnotetext{
9 González Fernández (2015): 54-56.

10 Aguilar (1985b). 72-73.

$11 \quad$ Linz (1988): 71.

12 Pérez Díaz (1987): 129.

13 Tuñón de Lara (1967).
} 
verdaderas alianzas», y cuando "esas relaciones son suficientemente intensas, tenemos un grupo que actúa según una lógica de grupo en ámbitos diversos como la política, los negocios, la relación social, etc.». Para este autor, cuando se anula «al empresariado como posible actor colectivo con capacidad de influir en la evolución histórica de Espańa en el siglo XX», se está desviando sus actos ("y las "culpas"») hacia otros actores (la clase política) que podrían "considerarse igualmente entelequias carentes de una voluntad común o de una identidad propia ${ }^{\prime 4}$. Por último, Pro también nos advierte del riesgo que se esconde tras el hecho de que «un sector mayoritario de los contemporaneístas ha orillado la relación entre poder económico y poder político, cuando anteriormente, bajo la égida de los estudios marxistas y la Escuela de Annales, «estaban en el centro de su atención» ${ }^{15}$. Sirvan las siguientes páginas para conjurar, siquiera modestamente, este peligro.

\section{LOS AÑOS CRÍTICOS: EL DESAFÍO AL ORDEN CAPITALISTA Y LA CONTRARREVOLUCIÓN CONSERVADORA}

Las elevadas tasas de crecimiento registradas tras el fin de la Segunda Guerra Mundial dieron paso a finales de la década de 1960 a la aparición en los países desarrollados de síntomas de agotamiento del modelo de acumulación capitalista de inspiración keynesiana. La «sensación global de insatisfacción», en palabras de Josep Fontana, que presagia el final de los ańos dorados del capitalismo, se manifiesta en los movimientos de protesta social en los Estados Unidos y en la Europa no socialista, que a menudo se superponen e incluso desbordan las tradicionales formas de lucha de la clase obrera. Esta dinámica de enfrentamiento contra la autoridad, junto con la emergencia de nuevos actores colectivos organizados fuera de los cauces de participación habilitados por el sistema, pusieron en guardia a la intelligentsia capitalista.

La crisis económica mundial, que estalla en 1973 tras el alza de los precios del petróleo por efecto de la guerra del Yom Kippur, impulsó la búsqueda de un nuevo orden económico emparentado con el liberalismo clásico, que diera respuesta al desafío planteado por la contracultura y la izquierda política, y permitiese liberar las correas del "capitalismo embridado» ${ }^{16}$. En esta batalla de las ideas, donde estaban en juego la supervivencia del sistema de libre empresa y propiedad privada, pero también el retorno de valores

\footnotetext{
14 Pro (1997): 298.

15 Pro (2007): 25.

16 Harvey (2007): 17.
} 
tradicionales como la afirmación del individuo frente a la intromisión estatal, iban a jugar un papel destacado las organizaciones empresariales. En Portugal, la Revolução dos Cravos iba a demostrar la necesidad de reagrupar a las fuerzas del capital, adormecidas tras el largo paréntesis paternalista del salazarismo.

No obstante, el intervencionismo empresarial en la política interna de las sociedades europeas occidentales iba a tener su fundamentación teórica al otro lado del Atlántico. Esta geografía del pensamiento no fue producto del azar, pues a los Estados Unidos habían llegado desde el viejo continente los principales teóricos de la contrarrevolución conservadora en ciernes, como F. A. Hayek, L. Von Mises o Ayn Rand. En los años siguientes, una red de fundaciones y think tanks de ideología conservadora estudian la crisis de gobernabilidad de las economías desarrolladas y tratan de legitimar una mayor participación de los poderes económicos. La hipótesis de partida es sugestiva: la democracia sufre una crisis de legitimidad porque sus instituciones son incapaces de satisfacer unas demandas sociales en aumento. Esta «sobrecarga» estaría obligando a los Estados a un mayor intervencionismo y a un aumento de su capacidad recaudatoria, mientras se favorece una política de transferencia de rentas desde el capital al factor trabajo.

Esta es una de las tesis principales del célebre estudio encargado en 1975 por la Comisión Trilateral al grupo compuesto por los sociólogos Michael Crozier y Joji Watanuki, junto al conocido politólogo Samuel Huntington, quienes alarmados por la «disgregación de intereses» en el cuerpo social y la participación creciente de la ciudadanía, recomendaron imponer limitaciones al sistema liberal democrático; un análisis planteado desde presupuestos economicistas que venía a ser, en palabras de Foucault, la «definición del costo económico del ejercicio de las libertades» ${ }^{17}$. Según este informe, la situación era especialmente grave en los países europeos, dada la mayor vulnerabilidad de sus Gobiernos para enfrentar una escasez de autoridad y recursos ${ }^{18}$. Como alternativa ideológica al socialismo y al capitalismo de Estado, la influencia de la doctrina trilateral es perceptible en los programas económicos de las administraciones de Carter y Reagan en los Estados Unidos y Thatcher en el Reino Unido, diseñados bajo las coordenadas monetaristas avanzadas por Hayek y la Escuela de Chicago de Milton Friedman: desregulación, privatización, control de la inflación sobre el empleo y flexibilización del mercado laboral.

La puesta en marcha de programas de orientación neoliberal exigía la implicación de los poderes económicos. Esta fue la principal contribución de

17 Foucault (2007): 90.

18 Crozier et al. (1975). 
otro informe, en esta ocasión encargado en 1971 por la Cámara de Comercio norteamericana al jurista Lewis Powell, un abogado corporativo en camino de convertirse en figura destacada del conservadurismo americano desde la Corte Suprema. El Manifiesto capitalista de Powell ${ }^{19}$, que inspiró a influyentes filántropos de la causa conservadora ${ }^{20}$, preconfigura el modelo de intervención del poder económico en la vida pública de las siguientes décadas. Su diagnóstico es similar al realizado cuatro años más tarde por la Trilateral: la crítica de «los extremistas de la izquierda» al sistema de libre mercado y a la libertad individual está socavando los valores tradicionales de la sociedad norteamericana. La novedad de este ataque, sostiene Powell, está en su amplitud, coordinación y en la tolerancia del sistema a su "propia destrucción». En efecto, la principal preocupación no se encuentra en los actores políticos que tradicionalmente han sido hostiles al sistema, "una pequeña minoría» en los Estados Unidos, sino en círculos más amplios de la comunidad intelectual, en las principales universidades, en medios de comunicación y en los sectores políticos liberales.

No obstante, la habilidad de Powell consistió en incitar a la movilización de los hombres de empresa, tanto empresarios a título individual como la tecnoestructura de managers y directivos, que habían respondido a esta agresión ignorando el problema; había llegado el momento de pasar a la acción política directa, asumiendo un papel más activo en la defensa de la libertad económica, cuya restricción precipitaría la del resto de libertades. Para ello, el informe planeaba la ejecución de un vasto programa de acción dirigido por las organizaciones profesionales y financiado por las grandes empresas. El plan establecía ámbitos prioritarios donde neutralizar la infiltración de la propaganda subversiva: la comunidad universitaria, el sistema judicial, la cultura y la vida política. Respecto de esta última, «there should be not the slightest hesitation to press vigorously in all political arenas for support of the enterprise system. Nor should there be reluctance to penalize politically those oppose it $\nu^{21}$.

\section{EL «APOLITICISMO» PATRONAL}

Los años setenta vieron el surgimiento de un clima de solidaridad empresarial internacional; no en vano el capitalismo tuvo que enfrentarse en estos

\footnotetext{
George (2007): 210

Phillips-Fein (2009): I62-I65.

21 "The attack on the free enterprise system», agosto de 1971. Una versión traducida al castellano en www.mientrastanto.org.
} 
años a problemas similares como resultado de un crecimiento anémico y del fenómeno hasta entonces cuasi desconocido de la estanflación ${ }^{22}$. Las turbulencias económicas pronto dieron paso a un incremento de las tensiones sociales que, con ciertos matices, enlazaron con el clima de protesta surgido a finales de la década anterior. En este contexto, los patronatos francés y español observaron con preocupación el auge del sindicalismo obrero y el cuestionamiento de la jerarquía en los centros de trabajo.

Francia es uno de los países donde se desarrolla de forma prematura la crisis del capitalismo. Los sucesos del Mayo del 68 servirán para instruir a una desorientada clase empresarial sobre los peligros de una "crisis de civilización», como la denominó André Malraux, larvada durante los años del gaullismo. Los efectos de esa crisis que pocos previeron motivaron en los cuarteles de la avenue Pierre-I-de-Serbie ${ }^{23}$ una profunda reflexión acerca de los riesgos de contemporizar con el enemigo. La clase trabajadora francesa, que había impugnado en el crisol reivindicativo de las jornadas parisinas el reparto de los beneficios derivados del ciclo expansivo, lograría en el siguiente lustro el mayor avance de los derechos sociales desde la Liberación ${ }^{24}$. Sin embargo, el estallido de la crisis energética y la caída de los márgenes empresariales modificaron los términos de una política de apaciguamiento que algunos dirigentes patronales interpretaron como el coste de elegir «la paz social en contra de la razón económica ${ }^{25}$. Se imponía ahora, bajo el criterio de los organismos financieros internacionales, el establecimiento con urgencia de medidas de ajuste de signo estabilizador y una nueva política de rentas que, en el caso de esta última, presentaría un carácter menos coyuntural.

En el ámbito político, el peligro de una unión de la izquierda francesa en el llamado "programa común de gobierno", y su posible efecto sobre la aplicación de políticas de ajuste, obligó a un notable esfuerzo de la clase capitalista. Las elecciones presidenciales de 1974 celebradas tras la muerte de Georges Pompidou estuvieron precedidas de una intensa campaña de movilización del voto y agitprop patronal en contra de las opciones marxistas, sin contar con las generosas subvenciones directas a los partidos del centro derecha ${ }^{26}$. En este sentido, fue muy comentada la actuación de la poderosa Unión de Industrias Metalúrgicas y Mineras (UIMM), federación

22 La crisis en el contexto español en Rojo (1987); García Delgado y Serrano (1990), y Fuentes Quintana (1989).

23 Sede histórica del CNPF.

24 Boltanski y Chiapello (2002): 264-265.

25 Collombat y Servenay (2014): 201.

26 Garrigues (2006): 95. 
integrada en la estructura del CNPF, pero con una amplia libertad de acción; de sus arcas salieron cuantiosas aportaciones para la logística electoral de Giscard d'Estaing.

Años después, la resonante victoria de Mitterrand en las presidenciales de 1981, pese a la nueva campaña empresarial en apoyo de Giscard, no fue interpretada por el patronato español como una advertencia acerca de los riesgos de involucrarse a fondo en la arena política. Como señaló más tarde uno de los presidentes del CNPF, Yvon Gattaz, la toma de posición del empresariado en contra del candidato socialista no solo no funcionó como habían diseñado los estrategas patronales, sino que sirvió para levantar una barrera infranqueable entre el CNPF y el presidente electo ${ }^{27}$. Sin embargo, la lección que más influiría en la estrategia política de la CEOE tenía que ver con otra de las explicaciones del patronato galo a la derrota de Giscard: la división presente entre las fuerzas conservadoras (la campaña de Chirac) y el deslizamiento hacia Mitterrand de un porcentaje importante del voto gaullista.

La trayectoria de la organización cúpula del empresariado español presenta desde su creación en 1977 paralelismos con su homóloga francesa, con quien comparte una fluida relación y unos adversarios comunes. La etapa de Carlos Ferrer Salat al frente de la CEOE (1977-1984) coincide con un significativo incremento de la injerencia del mundo económico en el sistema político, terminando así con la «marginalidad privilegiada» adoptada por los hombres de negocios dentro de la maquinaria de poder franquista ${ }^{28}$. Un papel secundario que no impidió a industriales y terratenientes, beneficiados por la política de rentas y el control de la clase trabajadora impuestos por los vencedores de la Guerra Civil, mantener una elevada capacidad de influencia sobre el personal político y la alta administración del régimen, aunque a menudo esta tuvo lugar fuera de los cauces oficiales ${ }^{29}$.

La crisis internacional y su correlato en España agudizaron la imagen negativa que arrastraba la figura del empresario, «al que se identificaba como uno de los principales sostenedores y beneficiarios del franquismo ${ }^{30}$. Esta realidad obligó a una modificación del lenguaje empresarial que propiciase la paz social mientras se allanaba el camino a la aceptación por las fuerzas políticas y sociales de un programa de ajuste económico, ya perfilado en sus líneas básicas en los Pactos de la Moncloa (1977). De manera un tanto inesperada, estos acuerdos, que significaron «el inicio de una nueva etapa del

\footnotetext{
Gattaz (1988): 63.

Cabrera y Rey Reguillo (2002): 303.

9 Molinero e Ysàs (1998): 78.

30 González Fernández (2007): 169.
} 
capitalismo español ${ }^{31}$, fueron ampliamente contestados por los dirigentes patronales, que lamentaron el anuncio de una política monetaria restrictiva y «el carácter progresista de las contrapartidas de la política de ajuste», pero que también otearon en la crítica al Gobierno la oportunidad de reforzar ante sus bases la incipiente organización ${ }^{32}$.

El principal argumento que esgrimió la patronal fue acusar al Gobierno de no haber contado con los agentes sociales en la elaboración de los pactos ${ }^{33}$. Lo cierto es que los hechos no fueron exactamente así: si bien la CEOE se lamentó de que el pacto salarial no fuese el resultado del entendimiento entre empleadores y trabajadores, una delegación de la recién constituida patronal que se entrevistó con el titular de Trabajo, Jiménez de Parga, informó al ministro de que prefería mantenerse al margen de la imposición de límites salariales, y de que esta ingrata tarea debía recaer exclusivamente en el Gobierno:

Nosotros [CEOE], por el contrario, entendíamos que, siendo el punto clave de las medidas económicas el de la moderación salarial, los límites máximos deben ser fijados imperativamente por el Gobierno [...]. La moderación salarial es algo muy difícil de aceptar y, para ello, se debe mentalizar a las personas en una política de austeridad. Esto solo puede hacerse por los poderosos medios de comunicación social que nadie más que los Gobiernos pueden mover.

El Ejecutivo, que se comprometió en la reunión a no indexar los salarios, debía abstenerse de desplazar el problema a las empresas: «En el momento en que nos sentáramos a negociar con las centrales sindicales y les dijéramos que ni siquiera el $17 \%$ podemos pagar y que solo es posible ofrecer 10 o 12 puntos menos que el aumento del coste de la vida, la reacción antiempresarial e irreprimible será muy fácil y podría salpicar al Gobierno» ${ }^{34}$.

Además de la coyuntura económica y política, el avance del paradigma neoconservador, junto con el rearme moral del empresario que se estaba operando en Occidente, influyeron en el alumbramiento del nuevo hombre de negocios español. Algunos de los elementos más característicos de la retórica del laissez-faire, hábilmente combinados con alusiones a una justicia social de reminiscencias cristianas, están presentes en dos panegíricos de temática

\footnotetext{
31 Etxezarreta (1991): 38.

32 Trullen (1993): 160.

33 La actitud empresarial ante los Pactos de la Moncloa, en Cabrera (2011).

34 Informe confidencial de la reunión celebrada el día 27-7-1977 en el Ministerio de Trabajo. Archivo personal de Carlos Ferrer Salat (en adelante ACFS), caja 18.
} 
empresarial que aparecen casi de manera simultánea en las páginas de La Vanguardia, cuando la transición democrática está dando sus primeros pasos. En el primero de ellos, el economista catalán Ramón Trías Fargas advertía al empresariado de las consecuencias de proseguir con su aislamiento del proceso político, pues parecía más interesado en tomar «acciones defensivas el día de mañana en vez de ser la vanguardia del cambio desde ahora». En medio de la incertidumbre provocada por una clase política empeñada en demostrar su fidelidad a los principios del Movimiento, Trías Fargas cree llegado el momento para que los hombres de negocios, caracterizados aquí como heraldos de la libertad y agentes del cambio siguiendo el enfoque schumpeteriano, abandonen «una alianza que no les conviene» e influyan sobre los poderes públicos para el advenimiento de una "democracia entera, lisa y llana " $^{35}$.

Con tres semanas de diferencia - la cronología apunta al estado de desorientación en el que vive instalada la clase capitalista—, aparece el célebre artículo de Luis María Ansón «La rebelión de los empresarios»" ${ }^{36}$. El texto está impregnado de un fervor casi religioso al narrar las gestas de los capitanes de empresa en la formación del capitalismo español, mientras se ensalza la figura del emprendedor al que la sociedad ve injustamente "como el villano de la historia», pasaje donde Ansón parece inspirarse en la literatura libertaria norteamericana y en su máximo exponente, Ayn Rand. En su obra más conocida, La rebelión de Atlas, esta filósofa de origen ruso, principal teórica del objetivismo y una de las pensadoras más influyentes del movimiento conservador hasta nuestros días, caracteriza al empresario como un Titán que se rebela, desde un individualismo íntegro y creador, contra la amenaza de las libertades ejecutada por el Estado colectivista ${ }^{37}$.

La estrategia política de la CEOE durante la Transición presentó dos vectores fundamentales: impedir o retrasar el acceso al poder de las izquierdas en los distintos niveles de la nueva configuración territorial e impulsar la reorganización de las fuerzas conservadoras en el proyecto de la "gran derecha», con los elementos moderados de UCD salvados del naufragio del partido gubernamental, más el personal reunido en AP en torno a Manuel Fraga $^{38}$. Para este doble propósito, la patronal movilizó ingentes recursos humanos y económicos, procedentes estos últimos de la banca y de grandes empresas cuyo modelo de negocio dependía del BOE. Un tercer objetivo

\footnotetext{
35 «Empresarios de toda España: uníos», La Vanguardia, 11-4-1976.

36 "La rebelión de los empresarios», La Vanguardia, 2-5-1976.

37 La influencia del artículo de Ansón en la génesis de la nueva patronal es confirmada por uno de los fundadores de CEOE, Eduardo Bueno, en $A B C, 30-11-1983$.

38 Hopkin (1993): 202.
} 
estaba implícito en los planes de la CEOE: fortalecer la representatividad de la nueva organización entre sus propias bases y presentar una única voz sobre los temas que importaban a los empresarios de todo el país, aun cuando fuera necesario silenciar otras voces.

El ciclo 1980-82 marcará el momento culminante de la intervención patronal en la vida política española, una influencia que había ido en aumento desde los primeros Gobiernos democráticos de la UCD. Existen pocas dudas sobre la responsabilidad de los círculos financieros y empresariales en el clima de fronda desatado contra Adolfo Suárez, al que acusaron de aplicar un marcado sesgo socialdemócrata en su programa de gobierno. La CEOE observó con interés la inquietud que provocaba en sectores de la sociedad de marcada tendencia conservadora la deriva que estaba tomando el proceso transicional en temas como la descentralización autonómica, el pluralismo político o la violencia terrorista, una situación que condujo a que determinados cenáculos de poder, donde se reunían militares, políticos, periodistas y representantes del mundo de los negocios, anhelaran un "golpe de timón» de impostada constitucionalidad que corrigiese la política seguida hasta entonces ${ }^{39}$.

La participación del gran capital en la financiación de la función política partió de la propia debilidad de los partidos para equilibrar una contabilidad que a duras penas alcanzaba a cubrir una parte de los gastos de organización y aquellos derivados de las actividades electorales. En cierto modo, se trató de una relación deseada por ambas partes, pues venía a paliar un problema de autofinanciación que por añadidura también sufrían otros partidos del entorno democrático europeo ${ }^{40}$. Desde el punto de vista del capital, esta debilidad institucional fue interpretada en términos de oportunidad para tutelar, como sistema privado de poder, el orden parlamentario y acrecentar su capacidad de influencia en los procesos públicos de toma de decisiones. En parte, esta voluntad era el reflejo de la ausencia de una cultura política democrática en un sector amplio del empresariado y la banca, cuya desconfianza hacia las nuevas instituciones tenía un precedente en los años treinta. Ciertamente, en el origen de la movilización patronal durante la Segunda República (19311936) estuvo la inestabilidad de su sistema político y el miedo a los cambios sociales, pero también el «sentimiento de haber perdido los contactos y la

39 La presencia empresarial en la trama civil del 23-F en García Crespo (2016); Bolaños (2012): 99-102, y Cercas (2009): 55-59. Algunos protagonistas han apuntado a una intervención directa de dirigentes de CEOE: Guerra (2005): 309 y San Martín (2006): 490.

40 Castillo (1985). Un análisis de la legislación en materia de financiación de los partidos, en Ruíz-Rico (2015). 
capacidad de presión sobre quienes tomaban las decisiones», junto con el estado de desorganización, al menos hasta la aparición de la CEDA, en el que se hallaba la derecha política ${ }^{41}$.

No es difícil ver ciertos paralelismos en las actitudes empresariales durante la Transición, aunque con un desenlace diferente. Si la crisis económica, el miedo a la clase obrera, la ausencia de un «partido de los patronos» o la desconfianza hacia el reformismo del nuevo personal político fueron elementos comunes a ambos períodos, la reacción de los líderes empresariales tras el fin del franquismo se orientó más hacia la participación en el juego democrático y no tanto a la búsqueda de soluciones de corte autoritario —Gobiernos de «salvación nacional» al margen-.

El procedimiento de financiación de los partidos y sus cuadros dirigentes, fuera de los cauces establecidos para ello, se puso en marcha con ocasión de las primeras elecciones generales celebradas en junio de 1977 mediante donaciones y créditos no reembolsables a las fuerzas afines ${ }^{42}$. La creación de la organización cúpula patronal racionalizó esta estructura, pues a partir de entonces las aportaciones privadas se canalizaron a través de CEOE que, desempeñando una función de bróker, fortalecía su posición como grupo de presión mientras movilizaba recursos para su proyecto político.

\section{PATROCINANDO LA «MAYORÍA NATURAL»}

Se ha señalado el «abandono» que sufre UCD desde 1980 por los poderes económicos como uno de los factores que explicarían su ocaso ${ }^{43}$. Y es un hecho que en la propia CEOE se instalaron las dudas sobre la viabilidad del proyecto centrista incluso con anterioridad a las derrotas en las elecciones autonómicas de Galicia (octubre de 1981) y Andalucía (mayo de 1982). Tras un encuentro celebrado entre Leopoldo Calvo-Sotelo, recién investido presidente, y Carlos Ferrer Salat, el dirigente patronal lamentaba su «falta de visión» al desentenderse de la organización del partido: «Con un presidente del Gobierno con el poder enorme que eso representa y mostrando una indiferencia auténtica y profunda respecto a la función de un partido, no hay

41 Cabrera y Rey Reguillo (2002): 231.

42 El mecanismo de financiación en Díaz-Varela y Guindal (1990): 61. Charles Powell (2001: 193) señala la importancia de las contribuciones de las grandes empresas del sector eléctrico, las cuales, según mis estimaciones, debían de superar las de la banca.

43 Jáuregui (1987): 87; Álvarez de Miranda (2013): 233, y Morán (2009): 245. 
ninguna posibilidad de futuro. Veía yo en aquel momento con toda claridad que UCD estaba perdida ${ }^{44}$.

A pesar de que la elección de Calvo-Sotelo fue recibida en el auditorio empresarial de manera favorable (no en vano el anterior vicepresidente para Asuntos Económicos era «uno de los suyos»), la simpatía inicial fue dando paso al desencanto, término recurrente en aquellos años, sobre todo a partir de las negociaciones del Acuerdo Nacional de Empleo (ANE) y la subvención del Gobierno a UGT y CC. OO. a cuenta del patrimonio sindical. Este episodio creó una profunda brecha entre la CEOE y el presidente, mientras el ministro «socialdemócrata» de Economía, Juan Antonio García Díez, era convertido en diana de las invectivas patronales ${ }^{45}$.

La crisis abierta entre el Ejecutivo y la confederación empresarial antes del verano fue parcialmente resuelta en los siguientes meses, aunque las opciones de Calvo-Sotelo para liderar el centro derecha español, nunca descartadas por la cúpula patronal, quedaron comprometidas. También preocupaban en la CEOE las conexiones del presidente del Gobierno con lobbies económicos como el Círculo de Empresarios ${ }^{46}$, así como el apoyo de algunos barones ucedistas a otras organizaciones profesionales, desempeño en el que sobresalió Agustín Rodríguez Sahagún y que suponía una amenaza al férreo control ejercido por la CEOE en el mundo empresarial.

¿Podemos afirmar que el partido que dirigió la transición a la democracia quedó huérfano del apoyo del mundo empresarial? No exactamente. De otro modo, sería difícil explicar que UCD no dejase de recibir fondos canalizados a través de CEOE hasta su disolución en 1983. Asimismo, una ruptura abierta con Calvo-Sotelo no parecía la mejor opción para controlar el aparato del partido, donde los suaristas aún mantenían amplias cuotas de poder, ni para evitar un acuerdo con los socialistas. Tampoco parecía una maniobra inteligente romper con el Ejecutivo mientras se negociaban importantes reformas en materias de interés - fiscal, laboral, energía, comunicación - para el sector privado, sin olvidar las negociaciones para la adhesión a la $\mathrm{CEE}^{47}$. Esto no evitó que el precario equilibrio instalado en las relaciones Gobierno-CEOE estuviera a punto de saltar por los aires en varios momentos. Así, tras las feroces críticas vertidas por Ferrer Salat en su discurso de renovación de mandato,

44 Diario personal de Carlos Ferrer Salat (en lo sucesivo DPCFS), apunte del día 3-3-1981.

45 Las relaciones entre patronal y gobierno en Calvo-Sotelo (1990): 157-177.

46 Círculo de Empresarios (2013): 176-178.

47 La intervención empresarial en las negociaciones para la integración de España en la Comunidad Europea es analizada en profundidad en García Crespo (2019). 
el presidente amenazó con dimitir: «Si me veo atacado por la izquierda por el tema de la OTAN o [por el] director de la TVE, y por otra parte me veo atacado por la CEOE y por el empresariado desde otro ángulo, yo dimito y te dejo el poder a ti, a Felipe González o al Sr. Carrillo» ${ }^{48}$.

El mismo rey Juan Carlos transmitió a Ferrer Salat sus dudas sobre si era mejor que UCD y AP se presentasen por separado o coaligados. Además, «el monarca se mostró preocupado por la lamentable situación de UCD. Estimaba que Calvo-Sotelo y Adolfo Suárez deben colaborar. Deben trabajar conjuntamente. Pero que Adolfo Suárez no debe tener protagonismo político [...]. Se mostró preocupado por que ganaran las izquierdas las próximas elecciones. Cree que las Fuerzas Armadas no tolerarían un Gobierno socialista. Ello podría acabar con el Gobierno, con la Monarquía y con la democracia» ${ }^{49}$.

Sin embargo, dentro de la cúpula patronal nadie se engañaba respecto de las posibilidades reales de UCD para repetir legislatura. Tras la dimisión de Suárez y la celebración del II Congreso de Palma, en la planta noble de la CEOE se elaboraron planes para una "disolución controlada» del partido con vistas a la formación de la "gran derecha», mediante una criba de las familias políticas presentes en sus centros de poder (Gobierno, grupo parlamentario y partido). La solución que contaba con más apoyos preveía la salida del sector socialdemócrata y de algunos dirigentes suaristas, como el citado Agustín Rodríguez Sahagún o Rafael Calvo Ortega (que dirigían el partido después del congreso $)^{50}$, para reunir una nueva fuerza con elementos de la familia democristiana presentes en el grupo parlamentario, con Óscar Alzaga como hombre destacado (que contaba con importantes apoyos tanto en la CEOE como entre la jerarquía eclesiástica), más efectivos reclutados en ayuntamientos y en organizaciones como Acción Católica ${ }^{51}$. Sin embargo, los informes

48 «Entrevista con el presidente del Gobierno, Leopoldo Calvo-Sotelo», 3-11-1981. DPCFS.

50 Celebrado los días 6-8 de febrero de 1981. El resultado de este segundo congreso de la organización es interpretado por Jonathan Hopkin (1999: 243) como el punto de partida para la construcción de una alternativa electoral a UCD a partir de sus sectores conservadores y con el patrocinio de CEOE, que no ve más opción que el «desmantelamiento" del partido. Si atendemos al testimonio de Alberto Oliart, varias veces ministro durante los gabinetes de Suárez y Calvo-Sotelo, la negativa de este último a expulsar a los socialdemócratas del Gobierno sería el momento en el que la derecha económica decidió provocar la «ruptura controlada» de UCD. Alonso-Castrillo (I996): 55I.

51 La CEOE mantenía por entonces una relación de patronazgo con la Fundación Humanismo y Democracia, entidad creada en 1977 y dirigida por la familia democristiana de UCD. 
internos manejados por Carlos Ferrer Salat alertaban de dos riesgos en esta operación para constituir un «lobby político católico»: en primer lugar, que dada la estructura del electorado español, «no parece posible que este partido llegara a poder atraer todo el voto de la derecha española», y en segundo término, teniendo en cuenta la doctrina social de la Iglesia y la influencia de otros partidos democristianos como el italiano, alejados del neoliberalismo anglosajón que practicaba la cúpula de $\mathrm{CEOE}$, este sector podría no mostrarse totalmente favorable a "un modelo económico netamente capitalista ${ }^{52}$.

Ante un hipotético fracaso en la toma del control de UCD, los democristianos, junto con algunos independientes y los miembros de la facción liberal bajo la dirección de Ignacio Camuñas, podrían concurrir, gracias al manejo adecuado de sus vías de financiación, «en candidaturas unitarias en fórmula análoga a Alianza Democrática Portuguesa $»^{53}$. En efecto, la coalición de partidos del centro derecha portugués liderada por Francisco Sa Carneiro, que se alzó con la mayoría absoluta en las elecciones legislativas de 1979 tras derrotar a los socialistas de Soares y los comunistas de Cunhal, se convirtió en modelo de los planes de la derecha económica española. Todavía en los primeros meses del Gobierno de Calvo-Sotelo, la idea que cuenta con más apoyos en la CEOE consiste en una «alianza a la portuguesa» encabezada por el presidente, confiando en que tome las riendas del partido. Para reforzar su papel de líder de UCD, Carlos Ferrer Salat sugiere retrasar el apoyo económico de la patronal hasta que Rodríguez Sahagún, que preside la formación centrista, pida a Calvo-Sotelo que intervenga ante CEOE para obtener este apoyo, estrategia que acepta este último ${ }^{54}$. No obstante, Ferrer Salat conoce a través del vicepresidente y miembro del sector "aperturista» de AP, Félix Pastor, las dudas de Fraga sobre la operación, aunque el propio Pastor también veía riesgos en dar «una financiación sin condiciones a Alianza Popular para hacer una campaña electoral por su cuenta $\$$.

\section{LA «FÓRMULA MOLINAS»}

En 1980, con ocasión de los primeros comicios autonómicos en Cataluña, se dio el paso definitivo en la estrategia de intromisión empresarial

52 «Estrategia de cara a las próximas elecciones [generales]». ACFS, caja 20. En virtud de ciertas referencias presentes en el documento, su datación probable debe situarse en los primeros meses del Gobierno Calvo-Sotelo.

53 Ibid.

54 Reunión con Calvo-Sotelo, 13-4-1981. APCFS.

55 Reunión con F. Pastor, 30-4-1981. APCFS. 
dentro de la esfera electoral. En efecto, desde la dirección patronal se entendió que, dada la incapacidad de los partidos afines para frenar el avance de la izquierda, había llegado el momento de una intervención activa en las elecciones. El encargo recayó en la centenaria patronal Fomento del Trabajo, que «estableció el modo y manera de hacer política y de relacionarnos en el mundo empresarial con partidos y dirigentes políticos que todavía perduran ${ }^{56}$. Fomento, una de las organizaciones fundadoras de la CEOE, coordinaría con inesperado éxito la operación que debía «impedir que la Cámara catalana fuera ocupada por el marxismo " $"$. Las elecciones catalanas del 20-M iban a constituir un excelente experimento de campo con vistas a poner en práctica la capacidad del mundo empresarial para intervenir en las preferencias electorales.

Aunque hoy sabemos que aquellas elecciones significaron un giro importante del mapa electoral catalán y el inicio del proyecto de nacionalismo interclasista de inspiración conservadora de Jordi Pujol, los últimos resultados obtenidos por el Partit dels Socialistes de Catalunya en la doble cita electoral de 1979 (generales y municipales), donde fue la primera fuerza política, junto con los sondeos de las semanas previas, presagiaban una cómoda victoria - sin alcanzar la mayoría - a su cabeza de lista, Joan Reventós. Con el precedente de los pactos de izquierdas en los ayuntamientos, los socialistas catalanes preparaban el terreno para una reedición del «bloque de progreso» con Josep Benet y los comunistas del PSUC.

Junto con el predominio de la izquierda, los pronósticos avanzaban un fuerte retroceso del partido gubernamental en las urnas catalanas, tras el fracaso de la política autonómica de UCD en el referéndum andaluz. En el horizonte, crecía el riesgo de un repliegue de los partidos «nacionales» en el mapa político de las autonomías que habían optado por la «vía rápida» del art. 151, posibilidad que iba a plasmarse en las elecciones al Parlamento Vasco celebradas una semana antes que las catalanas, donde UCD y PSOE cedieron ante el empuje del PNV de Garaikoetxea.

Para entonces, el presidente de Fomento y hombre influyente en la cúpula de CEOE, Alfredo Molinas, había decidido liderar una operación de lobby político para decantar el voto hacia las opciones del centro-derecha catalán y evitar el efecto desestabilizador de un eventual Gobierno de orientación marxista. Ciertamente, como demuestra un análisis de la campańa, las posibilidades de que un eventual Govern de izquierdas acometiese un proceso de socialización de la economía o incluso de supresión de la propiedad privada eran casi nulas, pero esta circunstancia no detuvo la estrategia del miedo

56 Márquez (2012): 293.

$57 A B C, 11-6-1981$. 
patrocinada por Fomento y la CEOE. Ernest Lluch, miembro destacado del Círculo de Economía, intentó tranquilizar a la burguesía catalana señalando que los socialistas aplicarían «un esquema de coordinación y aplicación plenamente compatible con la economía de mercado ${ }^{58}$, y que su lucha se centraría en acabar con las prácticas monopolistas, tarea que el ilustre economista debía intuir compleja, por el alto grado de concentración financiera y empresarial de la economía española tras la etapa de aceleración de la práctica monopolista que tiene lugar durante los años del desarrollismo. Con todo, Reventós no ocultaba la tensa relación que mantenía con la actual directiva de Fomento, a pesar de los contactos recientes mantenidos con la patronal para el estudio de determinadas cláusulas del AMI, acuerdo marco interconfederal sobre negociación colectiva suscrito por CEOE y UGT en enero y que había contado con el apoyo de los socialistas.

La previsible victoria de Reventós, contemplada por el mismo Jordi Pujol, quien atisbaba un pacto postelectoral con el PSC, también era vista en términos de crisis de confianza del empresariado: un triunfo de las izquierdas provocaría un estado de «decaimiento general» tras una intensa movilización de las fuerzas empresariales, situación que podría complicarse si el nuevo Govern tomaba «represalias» contra la patronal. Pero ni las llamadas a la moderación dentro del mundo empresarial ni una posible fórmula postelectoral sociovergente terminaron de convencer a Molinas, quien viajó a París para recabar el consejo técnico del CNPF, que contaba con una amplia experiencia en el terreno del «dopaje» electoral ${ }^{59}$. Pese a que no se hizo pública la cifra concreta que Fomento destinó a ayudar a Convergència, ERC (para frenar la posibilidad, aunque remota, de que los republicanos sumasen sus votos a una coalición frentepopulista compuesta por el PSC y el PSUC), Solidaritat Catalana y el PSA de Rojas Marcos, que iniciaba una fructífera relación como instrumento electoral de la CEOE, sabemos que una parte correspondió a las aportaciones que cada empresario realizó en forma de cuestación, mientras que otra cantidad procedía del aparato de captación de CEOE. Desde Fomento se dieron instrucciones para que ningún empresario hiciese donaciones a título personal; los fondos con destino a los partidos debían canalizarse a través de la patronal ${ }^{60}$.

58 Tele/eXpres, 14-3-1980.

59 La asistencia proporcionada por el CNPF es confirmada por el periodista y político Manuel Milián Mestre (2016: 386), que participó activamente en la «Operación Fomento".

60 Casi 400 millones es el cálculo que hacen los periodistas económicos Díaz-Varela y Guindal (1990: 79) de la «Operación Fomento». 
Lewis Powell había intuido que la coordinación y la planificación de la acción empresarial, junto con una movilización sostenida de importantes recursos, serían esenciales para influir en la arena política y en la ciudadanía. Aunque en su análisis del teatro de operaciones norteamericano Powell había reservado a la Cámara de Comercio el mando ejecutivo, dentro del marco de representación corporativa en España ese papel solo podía recaer en las nuevas organizaciones patronales, que además contaban con el apoyo económico proporcionado por la banca, dada la escasez de los recursos propios. La estrategia electoral de Fomento partía de una realidad incómoda: buena parte del empresariado catalán había votado a los socialistas en anteriores consultas. Por este motivo, el objetivo principal de la denominada «campańa de sensibilización empresarial» consistía en convencer al empresario de que tomara "conciencia de la necesidad de ejercer su derecho al voto y lograr el mayor número posible de votos no marxistas» ${ }^{61}$. Además, los estudios electorales internos de Fomento aseguraban que la abstención perjudicaba al bloque de opciones a la derecha del PSC. Para tratar de convencer a los indecisos se apuntaban tres líneas de argumentación: reforzar el carácter nacionalista de Convergència, identificar de manera clara la afiliación marxista del PSUC («menos de la mitad de la población cree que el PSUC es un partido comunista») y subrayar la dependencia del PSC y del PSUC del exterior: no debían ser "percibidos como partidos de obediencia catalana» ${ }^{62}$.

La amenaza que representaba un Gobierno de ideología marxista para el sistema de libertades en Occidente impregnó buena parte de los mensajes electorales de Fomento, que identificaban una relación causa-efecto entre los ataques al modelo económico capitalista y la mutilación del conjunto de libertades de la ciudadanía. Aquí hallamos uno de los ejemplos donde el paralelismo con los argumentos contenidos en el Memorándum Powell es más estrecho: si en este se asevera que «As the experience of the socialist and totalitarian states demonstrates, the contraction and denial of economic freedom is followed inevitably by Governmental restrictions on other cherished rights», en el folleto editado por Fomento titulado «El futuro está en tus manos» (con una tirada de 679000 ejemplares), se asegura que «los procesos socializadores acaban siempre suprimiendo las libertades. No se conoce un solo caso - uno solo- en la historia de la Humanidad de libertad política sin libertad

61 «Campaña de sensibilización empresarial para las elecciones al Parlamento de Cataluña», diciembre de 1979. ACFS, caja 16.

62 "Cataluña-80. Informe sobre coyuntura electoral», enero de 1980. ACFS, caja 16. Este extenso estudio fue realizado por una consultora con sede en Madrid, por lo que es previsible que el contacto fuese establecido desde la CEOE. 
económica». Si en opinión del jurista conservador, "whatever the causes of diminishing economic freedom may be, the truth is that freedom as a concept is indivisible», el pasquín patronal subraya, sirviéndose del mismo epíteto, que "la libertad es indivisible, no admite ser tomada por parcelas» ${ }^{63}$.

El control de los medios de comunicación era determinante para el éxito de la operación. En las reuniones mantenidas con los principales accionistas de los grupos de comunicación más influyentes, se les advirtió de la socialización de los beneficios y de la pérdida del control sobre sus empresas que se derivaría de un triunfo de las opciones marxistas... Dada la importancia asignada a este sector, en la oficina de campaña circularon informes con análisis de agencias de noticias, diarios, y cadenas de radio y televisión, donde quedaba reflejada la ideología de editores, directores y subdirectores, la posición de cada medio (marxista o no marxista) y la posible actitud que se esperaba de ellos en lo relativo a la campańa empresarial (neutra, favorable o desfavorable). A modo de ejemplo, el cómputo de la prensa en Barcelona arrojaba los siguientes datos: de diez medios analizados, cinco tenían una ideología predominante «marxista» (El Periódico, Mundo Diario, Tele Exprés, Cataluña Exprés, Hoja del Lunes), de los que cuatro tenían una actitud desfavorable y solo uno «neutral» (Hoja del Lunes), mientras que en el grupo de los «no marxistas» (La Vanguardia, Avui, El Correo Catalán, Diario de Barcelona, El Noticiero Universal) dos de ellos eran favorables (Diario de Barcelona y El Noticiero Universal) y los tres restantes eran vistos como medios con una actitud neutral. En cuanto a las emisoras de radio, el análisis de sus servicios informativos mostraba que los mayores apoyos estarían en Radio Nacional de España, Radio Juventud y Radio España, mientras que la emisora de la Cadena Ser en Barcelona y Radio Miramar eran considerados medios hostiles ${ }^{64}$.

Además de la movilización entre sus afiliados, Fomento buscaba combatir la abstención con una llamada al conjunto de los ciudadanos «responsables», a los que se pedía que se convirtieran en «agentes concienciadores». La información debía ser "singularizada» según se tratase de empresarios, asociaciones de vecinos y amas de casa, clubes deportivos, gremios o maestros (a los que se enviaron seis mil cartas personalizadas). Aunque el rico entramado asociativo civil catalán era monitorizado desde Fomento, se dejaba en manos de

63 Este y otros anuncios pueden consultarse en los números de la revista Horizonte empresarial editada por Fomento correspondientes a los primeros meses de 1980. Más sorprendente resulta el hecho de que también se pueden encontrar en algún dossier del archivo histórico de la patronal francesa en Roubaix.

64 «Campaña de sensibilización empresarial para las Elecciones al Parlamento de Cataluña $[\ldots] »$, cit. 
los llamados colaboradores cualificados (editores, periodistas, economistas, escritores, políticos...) la misión de inducir un estado de opinión general que alertase acerca «de una ruptura radical y fuerte si ganasen los partidos marxistas, entre la Cataluña tradicional e histórica de una sociedad libre y democrática, a una sociedad estatificada y planificada de acuerdo con la ideología marxista» ${ }^{65}$.

Aunque se intentó en lo posible evitar la identificación de la campaña empresarial con un partido determinado, circunstancia que habría derivado en denuncias ante la Junta Electoral, como sucedió más tarde en las elecciones andaluzas, nadie podía desconocer qué formación contaba con las simpatías de la patronal. El doble discurso de Jordi Pujol, que revitalizaba el catalanismo conservador y que pretendía atraer a los segmentos populares con llamadas a la superación de marcos ideológicos y a la unidad del pueblo por encima de la lucha de clases, se situaba en las coordenadas del proyecto de sociedad industrial avanzada "posideológica» que comenzaba por entonces a vislumbrar el aparato ideológico patronal. «Son miles y miles los obreros que, a base de esfuerzos titánicos, se han transformado en autopatronos y en pequeños empresarios. Una sociedad que permite que el que vale salga adelante y se promocione no puede ser calificada de sociedad de lucha de clases. En todo caso, de sociedad competitiva, es decir, que valora al hombre por su voluntad de lucha y de progreso", advertía uno de los anuncios de propaganda electoral pagado con fondos empresariales. La solución a la crisis no estaba «en volver la vista a sistemas que no han conseguido solventar sus propios problemas y proporcionar una vida próspera a sus ciudadanos, sino en luchar solidariamente, empresarios y obreros» ${ }^{66}$.

En cuanto a la política económica, Fomento aceptaba el tono reivindicativo de Pujol cuando defendía una mayor asunción de competencias en materia comercial y fiscal junto con una mejora del programa de inversiones estatales, siempre que esta actitud no pusiera en riesgo la unidad de mercado con el resto de regiones y el marco único de relaciones laborales. Lo cierto es que en la patronal catalana tenían sus propios planes acerca de cuáles deberían ser los vectores económicos del nuevo Gobierno de la Generalitat. Se daba por hecho que la Administración catalana, en parte por la herencia recibida, no dispondría en los siguientes cuatro años «de la discrecionalidad de gasto que implica la Autonomía» y que, en todo caso, la crisis no podría "financiarse ni con incremento de impuestos ni con emisión de deuda». En cambio, sí se esperaba del Govern que saliese de las urnas la exigencia

65 Ibid.

66 «Suprimamos la empresa...¿y después?». La Vanguardia, 15-3-1980. 
continua del «cumplimiento de los programas de inversión pública del Estado en Cataluña», que afrontase «las dificultades que en los últimos años el planeamiento urbanístico ha impuesto a la construcción» y una denuncia permanente en Madrid de «todos aquellos defectos de la Administración central que dificultan la actividad económica privada» ${ }^{67}$.

\section{LOS GRUPOS OPERATIVOS REGIONALES}

El inesperado éxito cosechado en Cataluña reforzó la confianza empresarial y animó a la patronal española a repetir la «fórmula Molinas» en las siguientes consultas. Las elecciones celebradas en las comunidades gallega y andaluza, junto con las generales de octubre de 1982, estuvieron precedidas de un intenso trabajo de prospección social. La CEOE ordenó la creación de un grupo de trabajo reducido para coordinar las operaciones de cada región. Capitaneado por Fabián Márquez (estrecho colaborador de Martín Villa en la OSE y hombre de la absoluta confianza de José María Cuevas), Miguel Ángel del Río (procedente también del «vertical») y el sociólogo Pedro Arriola, el equipo ya había adquirido experiencia en la «orientación» del voto en las elecciones sindicales de esos ańos, donde consiguieron con indudable acierto que la central UGT neutralizara la ventaja de CC. OO.

Según los informes internos remitidos a la dirección de CEOE, entre los años 1981 y 1983 se procedió a desplegar en las provincias más importantes los denominados Grupos Operativos Regionales - GORES en el argot patronal- para movilizar el voto moderado. La nueva misión diseńada por el equipo demoscópico de Márquez, que venía a complementar la financiación de los partidos, mantuvo un carácter reservado, siendo únicamente conocida en toda su amplitud por un reducido núcleo de dirigentes de la entidad ${ }^{68}$.

67 «Reflexiones sobre un programa económico de la Generalitat», Fomento del Trabajo, s. f. ACFS, caja 15.

68 La implicación de GADES en las campañas electorales en El País, 4-9-1982. Los informes que se citan en este artículo, muchos de los cuales no estaban firmados, seguían un conducto confidencial: se remitían directamente a José María Cuevas, quien se los hacía llegar al presidente Ferrer Salat. También estaban al corriente varios miembros de la cúpula directiva y los bancos, que financiaron las operaciones. Entrevista a Fabián Márquez, 16-5-2018. Por otra parte, la relación del gabinete de asesores de Márquez con la dirección de la patronal y su formulación estratégica es en estos momentos muy estrecha. Sirva como muestra que, más allá del desempeño en el departamento laboral o en el diseño de las campañas electorales, la labores de 
Aunque las urnas ofrecieron resultados dispares, la valoración realizada por la cúpula de CEOE fue positiva. En las elecciones a la Xunta, la patronal gallega movilizó «hasta 1000 personas que iban cada día haciendo la campaña». Además, los grupos operativos «actuaron con gran eficiencia» ${ }^{69}$. En última instancia, los comicios demostrarían por primera vez, para satisfacción de buena parte del empresariado, que UCD cedía terreno ante el partido de Fraga en lo que hasta entonces había sido un feudo centrista. La clave del triunfo de AP debe buscarse en la «muy activa participación» de la organización empresarial, que no dudó en abandonar la neutralidad inicial para "condenar abiertamente a todos los partidos tocados de marxismo $»^{70}$. Ya entonces, Fraga había ido ganando apoyos en el mundo económico mientras intentaba «moderar sus postulados ideológicos y abandonar sus rasgos de partido antisistema ${ }^{71}$.

Frente a lo sucedido en anteriores comicios, la campaña para las autonómicas andaluzas trasladaría la contienda electoral a un escenario de gran virulencia, con denuncias ante las juntas electorales por una actuación de la patronal andaluza (CEA) que, a juicio de los partidos de izquierdas, vulneraba la legalidad electoral. La estrategia seguida por los empresarios, con constantes y directas acusaciones a los socialistas de pretender la revolución social, se convirtió en una campaña de solidaridad y promoción de los valores que encarnaba el hombre de empresa. Para Ferrer Salat, el presidente de la CEA, Manuel Martín Almendros, «era un héroe del empresariado, un héroe de la defensa de la libertad de expresión [...]. No solo aguantaba con perfecta fortaleza esta situación difícil, sino que al contrario le alentaba más [...]. El empresariado se daba cuenta de esta actitud de gallardía en defensa de todos los empresarios andaluces y del empresariado español» ${ }^{72}$.

La campaña del miedo tuvo finalmente un efecto «bumerán», al lanzar en brazos del PSOE «a unos 200000 antiguos votantes centristas y a una parte indeterminada de los 172000 simpatizantes perdidos por los andalucistas» ${ }^{73}$. Para el recuerdo quedaría la imagen del puño socialista y la manzana

este grupo incluían la realización de estudios e informes para las conferencias y artículos del presidente y el secretario general Cuevas, asistencia que posteriormente también se ampliaría al partido de Manuel Fraga.

69 «Elecciones para el Parlamento de Galicia», octubre de 1981, DPCFS.

70 Pérez Vilariño (1987): 68.

71 Montero (1987): I2.

72 "Campaña electoral para elegir a los diputados del Parlamento andaluz», 15-5-1982. DPCFS.

73 Caro (2015): 24. 
de la que salía un gusano con la hoz y el martillo, trasunto del reciente acuerdo entre socialistas y comunistas en el Gobierno asturiano. La idea del cartel, que partió de los asesores de CEOE en Madrid, tenía como objetivo movilizar al electorado conservador, no tanto para evitar la victoria socialista (casi segura a tenor de los sondeos internos de la patronal $)^{74}$, sino para consolidar un voto de derechas: «Se han creído que vienen los rojos» 75 .

En el discurso de los líderes empresariales se hicieron frecuentes las alusiones a la falta de legitimidad de la clase política y el parlamentarismo. En una de sus intervenciones con mayor carga ideológica, Ferrer Salat reconocía que «la política es algo demasiado importante para dejarla solo en manos de los políticos profesionales o de los burócratas ${ }^{76}$. De manera oportuna, el presidente de la patronal explotaba el sentimiento de desafección hacia la política que comenzaba a arraigar en una sociedad que parecía sumirse en un «extrañamiento afectivo» hacia sus representantes políticos, una actitud que se ha mantenido estable desde entonces ${ }^{77}$.

No obstante, esta desconfianza hacia la política expresada por la dirección de la CEOE no era indiscriminada. El objetivo prioritario de su estrategia política siempre radicó en frenar las perspectivas electorales del PSOE, incrementadas como consecuencia, según la visión patronal, de la penetración cultural de los valores de la izquierda en la sociedad postfranquista. Para ello, era imprescindible convencer a la opinión pública española, siguiendo el nuevo discurso neoliberal ensayado en el Reino Unido y los Estados Unidos, de que la libertad era preferible a la igualdad, de que era necesaria una bajada de los impuestos o bien de que un aumento del gasto público sería ineficaz para combatir el desempleo o la pobreza (interpretada esta como un fenómeno natural por autores con gran predicamento en la derecha económica española como Hayek o Friedman). Una misión que no parecía sencilla en una coyuntura de recesión económica y destrucción de puestos de trabajo, y

74 Según estas encuestas, un elevado porcentaje de pequeños empresarios (en torno al $40 \%$ «no distinguía entre UCD y PSOE»; además, muchos de ellos expresaban su intención de votar socialista, pues se consideraba a la formación de Felipe González «un partido más de orden que UCD», mientras el partido gubernamental «los cocía a impuestos». "Campaña electoral para elegir a los diputados del Parlamento andaluz $[\ldots] »$.

75 Entrevista a Fabián Márquez.

76 Discurso de C. Ferrer Salat ante la asamblea general de CEOE con motivo de su segunda reelección en la presidencia de la organización, 9-9-1981. Archivo Histórico de CC. OO., Fondo Consejo Confederal, sig. 44.01.

77 Montero, Gunther y Torcal (1999): 128-129. 
menos aún cuando en España seguía pendiente la construcción de un Estado del bienestar moderno.

La llegada de Reagan a la Casa Blanca a comienzos de 1981 fue algo más que un factor estimulante para la nueva clase dirigente patronal: aportaba la justificación y el procedimiento necesarios para implantar un estado de ánimo generalizado que facilitase la infiltración de los valores de la derecha. El grupo de asesores de la CEOE conocía con exactitud cómo se había formado alrededor del partido conservador norteamericano una amplia red de patronazgo ideológico en torno a organizaciones civiles como el American Enterprise Institute y la Fundación Heritage, un modelo que se pretendía implantar en España:

Se ha demostrado (la experiencia americana, con la llegada de Reagan al poder, es un buen ejemplo) que «sin teoría conservadora no puede haber movimiento conservador»; es decir, que cualquier partido político necesita de una amplia infraestructura que le alimente conceptualmente y que, mediante la creación de imagen oportuna, permita la penetración de los movimientos conservadores en la opinión pública, afianzando su influencia en los grupos sociales propicios ${ }^{78}$.

Estos think tanks eran los principales centros irradiadores del renovado pensamiento conservador. Más allá de su actividad principal como "centros de creación de ideología», existían otras funciones que podían importarse, como la preparación de "políticos prometedores», la instrumentación de «operaciones de marketing conservador» o la organización de campañas ${ }^{79}$. De hecho, la selección de cuadros políticos fue uno de los cometidos principales de la CEOE en estos años, que «disfrazó sus actividades de prospección de talentos para la derecha dentro de nuestra campaña lógica de constituir un patronato territorial en todo el país» ${ }^{80}$.

Para la intelligentsia empresarial, la convicción en las fuerzas propias que demostró en estos momentos la CEOE derivaba de su rápido reconocimiento como organización hegemónica en la defensa de los intereses empresariales (rompiendo de este modo con la fragmentación de etapas anteriores), pero también era el resultado de su habilidad en el ámbito de las relaciones sociolaborales para «manipular y operar sobre los sectores más delicados de [la]

78 «Notas para una Fundación», febrero de 1983. ACFS, caja 21.

79 «Planteamiento estratégico para los próximos años de Alianza Popular», junio de 1983. ACFS, caja 21.

80 Entrevista a Fabián Márquez. 
sociedad, el empresariado y la clase obrera, en defensa de un interés primordial: la consolidación social y el rechazo de la sistemática lucha de clases, como primera y única explicación del devenir social» ${ }^{81}$. Únicamente se trataba de extrapolar la capacidad de influencia de la patronal en este terreno al campo de la política.

La convergencia entre la CEOE y UGT en el marco de la concertación social iniciada en 1979, primera tentativa de un sistema de «mesogobiernos económicos» como vía para aplicar una política antiinflacionista, reducir la conflictividad laboral y legitimar la economía de mercado ${ }^{82}$, fue considerada un éxito en el patronato, pese a las reticencias mostradas inicialmente por su sector más liberal: «UGT ha sido capaz de girar sobre su propia derecha desarrollando una política moderada, hasta el momento, a impulsos de los compromisos suscritos con CEOE. Fuera de este contexto no se entendería la promulgación del Estatuto de los Trabajadores y la suscripción del $\mathrm{AMI}{ }^{83}$. Los pactos sociales fueron interpretados en la organización cúpula como un medio efectivo para la gobernabilidad del sistema; un cambio significativo en el marco mental del empresariado que llegaba tras décadas de prohibición de la libertad sindical.

Desde otro ángulo, el pacto con la UGT presentó para la confederación empresarial nuevas perspectivas en su estrategia de «conformar la expresión política de la derecha y la necesaria transformación de la izquierda para [...] racionalizar los distintos modelos de comportamiento" de un sistema — democrático- que se estaba configurando «aparentemente a espaldas de la voluntad empresarial ${ }^{84}$. Así, los meses de negociaciones con UGT permitieron a la patronal abrir una vía de diálogo con la nueva dirección del partido socialista. Dentro de los planes de la CEOE, se juzgó prioritaria la participación y aceptación final del Estatuto de los Trabajadores por parte del PSOE ${ }^{85}$.

Estos encuentros se intensifican en el otoño de 1980, cuando la situación de Suárez es más precaria y aumentan en los cenáculos de la capital los rumores de pactos para la formación de un nuevo Gobierno. En las reuniones que mantiene la CEOE con la Ejecutiva socialista, los dirigentes patronales tantean el terreno de posibles acuerdos a tres bandas (CEOE-UGT-PSOE) en materia económica, laboral y sindical. Al parecer, el PSOE transmitió su disposición a adoptar el plan de medidas contra el paro que la patronal había

\footnotetext{
81 «Creación de los Grupos Operativos Regionales», Madrid, 17-2-1981. ACFS, caja 19.

82 Pérez Díaz (1987): 74-94.

83 «Creación de los Grupos Operativos Regionales», cit.

84 Ibid.

85 Oliet (2000): 459.
} 
presentado a UGT y desarrollar de manera inmediata los acuerdos en los ámbitos donde gobernase. Además, el programa económico que esbozan Miguel Boyer, Enrique Barón y Ernest Lluch en estos encuentros, con menciones a la recuperación del excedente empresarial, el fomento del ahorro y un avance pausado de la integración en el Mercado Común, es acogido favorablemente por los interlocutores de la $\mathrm{CEOE}^{86}$.

Sin embargo, este diálogo no servirá para acortar la distancia que aún separaba la estrategia del patronato español y el proyecto político del PSOE. El mismo Carlos Ferrer Salat afirmará que hay que excluir cualquier solución basada en el engaño, pues el objetivo del principal partido de la oposición no es otro que «la socialización del sistema económico y fiscal [...] con acciones concretas que determinarán inevitablemente la asfixia de la iniciativa privada, en provecho de un sector público burocratizado e ineficaz» ${ }^{87}$. Tampoco Felipe González confiaba en obtener ningún rédito de unos acuerdos entre los agentes sociales que servían a la estabilidad del Gobierno ucedista, aunque la dimisión de Suárez hizo concebir esperanzas al jefe de filas del PSOE de obtener la presidencia. González compartió con los interlocutores patronales la posibilidad de obtener la mayoría necesaria si lo votan algunos disidentes de UCD, el PCE (sin entrar en el Gobierno) y algunas minorías regionales. Aunque es consciente de que no puede gobernar «sin la comprensión del empresariado", el jefe de la oposición también mostraba una absoluta confianza en conquistar el poder en las próximas elecciones generales ${ }^{88}$.

El vaticinio de González y la debilidad del Gobierno de Calvo-Sotelo impulsaron a la dirección del patronato a concebir una operación de «ingeniería social» para impedir el triunfo del PSOE. En su mencionado discurso ante la asamblea de CEOE, el presidente Ferrer Salat hará una llamada a la acción ante sus bases y anticipará que la atención de la patronal y de sus organizaciones confederadas estará puesta en «movilizar a todos los empresarios y a las fuerzas sociales que comparten nuestra concepción política, económica y social en apoyo de las opciones electorales y de los líderes que asuman expresamente este compromiso en una acción de gobierno coherente y eficaz» ${ }^{89}$.

86 Apuntes de Ferrer Salat de las reuniones celebradas los días 4-9-1980 y 10-9-1980. En estos encuentros están presentes las cúpulas de PSOE (González, Solana, Boyer, Barón, Lluch), UGT (Redondo y Zufiaur) y CEOE (junto al presidente, asisten José M. ${ }^{a}$ Cuevas, Carlos Pérez de Bricio y José Luis Cerón). ACFS, caja 15.

87 «Discurso de C. Ferrer Salat ante la asamblea general de CEOE [...]», cit.

88 Nota de Ferrer Salat sobre la reunión celebrada con Felipe González el 2-2-1981 en el restaurante El Parrillón. ACFS, caja 15.

89 «Discurso de C. Ferrer Salat ante la asamblea general de CEOE [...]», cit. 
Los grupos operativos desplegados en territorio nacional, compuestos por «un ejército directo y propio de la CEOE» reclutado entre antiguos contactos de los sindicatos verticales, tenían asignada una doble misión. En primer lugar, "captar y recoger toda la información colectiva e individual sociológica [...] para que a través de esos datos [se establezca] en el futuro y a corto plazo una programación política de presencia de la derecha real en los futuros comicios». En una segunda fase, se trataría de fijar en los distintos territorios «los correspondientes nexos de coordinación entre todas las personas, instituciones, asociaciones, empresas y entidades que, en el supuesto de una confrontación electoral bipolar, previsiblemente estarían dispuestas a apoyar la alternativa política de la derecha». La operación facilitaría «conectar el amplio mundo de las organizaciones empresariales con las clases y sectores conexos [...] fácilmente vinculables a la defensa de un programa común» y que incluían desde maestros (a través de sindicatos profesionales como AMPE) y padres de familia católicos, a funcionarios, directivos de empresa, miembros de las cámaras de la propiedad urbana, profesionales, amas de casa, etc. La idea, ensayada en Cataluña, era formar una estructura reticular de grupos e intereses concordantes para dirigir el voto en un sentido definido, un programa ambicioso que perseguía «la modificación de los espacios políticos en España, mediante los cambios en su base sociológica» ${ }^{90}$.

La magnitud de la operación se patentiza al reparar en la exhaustividad de los informes en aspectos como la adscripción ideológica de las entidades civiles susceptibles de ser captadas (colegios profesionales, asociaciones de vecinos, patronatos cívicos, casas regionales, clubes deportivos, etc.) o la información de carácter organizativo de las mismas (número de afiliados, organigrama, recursos económicos, instalaciones...). «Teníamos la información de quién era quién en todo el país» recuerda Fabián Márquez ${ }^{11}$.

La segunda finalidad del dispositivo consistía en articular y aumentar la afiliación del entramado asociativo del empresariado en las principales regiones. Ciertamente, la operatividad de estos grupos coordinados desde Madrid descansaba en el apoyo logístico que les proporcionaba la propia estructura local que convenía reforzar. A modo de ejemplo, la celebración de reuniones de trabajo con los «notables» provinciales y otras actividades de apoyo, como el envío de propaganda o las campañas de recaudación, se realizaban desde las territoriales.

A efectos de mejorar la coordinación, se formaron comisiones integradas por la élite local, con amplia representación del mundo de los negocios y la

\footnotetext{
90 "Informe de tareas llevadas a cabo, así como de acciones a realizar en el futuro», inicios de 1982. ACFS, caja 21.

91 Entrevista a Fabián Márquez.
} 
Administración, y cuyos miembros ostentaban o habían desempeñado cargos de relevancia dentro de la comunidad (presidentes de cámaras de comercio, delegados de Hacienda, directores de sucursales bancarias, concejales, exgobernadores civiles, dirigentes de sindicatos «independientes», presidentes de clubes deportivos, etc.). El informe de una de estas reuniones de «notables» celebrada en Tarragona evidencia la profunda imbricación entre empresarios y políticos a la hora de confeccionar las listas electorales de los partidos del centro derecha. Describe también cómo se "produjeron ataques vehementes contra UCD y CiU» mientras se detecta una creciente afiliación a AP del sector empresarial, lo que lleva a algunos de los presentes a plantear que $\mathrm{CEOE}$ apoye en solitario a AP contra el criterio establecido en la operación: «El intento se venció porque nuestros planteamientos son coherentes y no pueden ser rebatidos. Los restantes asistentes, e incluso los representantes de AP, reconocieron que nuestra postura era lógica» ${ }^{92}$. La desmoralización en las filas centristas según se aproximan las citas electorales de 1982 es reconocida por sus dirigentes locales. Un importante cuadro de Centristes de Catalunya-UCD en Gerona llegó a admitir que «entre Fraga y Calvo-Sotelo, él también elegiría a Fraga, porque el presidente no tiene imagen pública» ${ }^{93}$.

La operación de los denominados grupos operativos regionales se dio por concluida tras las elecciones del 28-O y el aplastante triunfo de González ${ }^{94}$. Las sucesivas victorias del PSOE retrasaron casi tres lustros la esperada alternativa de gobierno de aquella "mayoría natural» que sońaron los patronos, pese a lo cual la participación de la CEOE en la campaña arrojó algunos datos positivos: contribuyó a la cohesión del mundo empresarial y envió un claro mensaje al nuevo Ejecutivo: la aplicación del programa de gobierno socialista no sería viable sin contar con el apoyo patronal ${ }^{95}$.

\section{CONCLUSIONES}

Frente a otras etapas de nuestra historia reciente, los estudios sobre las organizaciones empresariales durante la Transición y el período democrático

92 «Seguimiento plan de actividades en Cataluña y Baleares», marzo de 1982. ACFS, caja 21.

93 Ibid.

94 El dispositivo continuó en marcha en algunas regiones, como Madrid, donde la patronal CEIM activó el Plan de Actuación Especial (PAE) con vistas a las elecciones autonómicas de mayo de 1983.

95 González Fernández (2010): 206. 
son aún escasos, a pesar de lo cual coincido con Ángeles González cuando señala que «determinar el papel que desempeńaron los empresarios en el proceso transicional y su participación en el denominado pacto social [...] resulta a todas luces necesario para obtener una visión más ajustada del tipo de democracia resultante en España » ${ }^{96}$.

La realidad que atestiguan unos parcos resultados en la estrategia electoral diseñada por la dirección de la principal organización patronal no debería inducirnos a juzgar como desdeńables los efectos de la injerencia empresarial en el sistema de partidos políticos y en las campańas electorales de este período, una intervención que plantea dudas acerca de su posible incompatibilidad con los principios de representatividad, participación y transparencia sobre los que se ha erigido la democracia española.

A pesar de los buenos datos obtenidos por las formaciones liberal-conservadoras apoyadas por el empresariado en Cataluña y Galicia, las amplias victorias cosechadas por el PSOE en Andalucía y, sobre todo, en las generales de octubre, que marcan el inicio de la larga presidencia de Felipe González, fueron interpretadas por la patronal como el fin de una época. Aunque no se alcanzó en 1982 el objetivo básico perseguido por la derecha económica, cabría preguntarse si fracasó del mismo modo el proyecto a medio y largo plazo trazado por los ideólogos de la CEOE: «Trascender el campo estricto de la derecha, toda vez que la aspiración más civilizada [...] de la clase dirigente del país debe proyectarse hacia un centro amplio que, desde la derecha a la izquierda moderada, garanticen una adecuada gobernación del mismo, sin poner en quiebra o peligro el modelo de sociedad basado en la libre empresa» ${ }^{97}$.

Ciertamente, la estrategia seguida por los dirigentes empresariales debe entenderse en un contexto amplio donde están presentes elementos internos, como la evolución del proceso transicional, las transformaciones de la estructura productiva o los cambios en el mercado laboral, junto con otros de carácter extrínseco como la crisis global del capitalismo, el ciclo revolucionario portugués y la revitalización del movimiento conservador a ambos lados del Atlántico. Las élites empresariales van a experimentar un proceso de aculturación a partir de la recepción y asimilación de las nuevas corrientes del pensamiento conservador y el paradigma neoliberal, cuya fundamentación teórica aporta elementos de análisis que son aplicados a la realidad española y legitiman la intervención en el sistema político de las organizaciones patronales.

Que la participación del empresariado como actor colectivo es decisiva en la misma gobernabilidad del sistema es un hecho que no puede ser ignorado.

96 González Fernández (2015): 47.

97 «Creación de los Grupos Operativos Regionales», cit. 
Nada hay de excepcionalidad en esta particular cogestión del dominio político, pues, como dedujo Wright Mills, "si hay intervención gubernamental en la economía organizada en grandes empresas, también hay intervención de esas empresas en los procedimientos gubernamentales» ${ }^{98}$. Por ello, no es de extrañar que la monitorización de la actividad política efectuada por la CEOE durante estos años, a pesar de las reiteradas afirmaciones de apoliticismo de sus dirigentes, constituyese una de sus principales actividades, a la que destinaron, como he tratado de mostrar, importantes recursos humanos y materiales con un objetivo inequívoco, aunque no siempre declarado: la instauración de un modelo de sociedad definido a partir de los intereses de clase, los cuales, como nos advirtió Santos Juliá, «no pueden dejar de interpretarse según los intereses propios de la organización. Y, más concretamente, según los intereses de la organización tal como los perciben sus élites dirigentes»" ${ }^{99}$.

\section{Bibliografía}

Aguilar, S. (1985a). ¿Burgueses sin burguesía? La trayectoria corporativa de la burguesía empresarial catalana. Revista Española de Investigaciones Sociológicas, 31, 183-211. Disponible en: https://doi.org/10.2307/40183128.

- (1985b). El asociacionismo empresarial en la transición postfranquista. Papers. Revista de Sociología, 24, 53-84. Disponible en: https://doi.org/10.5565/rev/papers/v24n0.1414.

Alonso-Castrillo, S. (1996). La apuesta del centro. Historia de la UCD. Madrid: Alianza.

Álvarez de Miranda, F. (2013). La España que soñé. Madrid: La Esfera de los Libros.

Bolaños, R. (2012). La involución militar durante la Transición. El golpe de Estado del 23-F [tesis doctoral inédita]. Universidad Autónoma de Madrid.

Boltanski, L. y Chiapello, E. (2002). El nuevo espiritu del capitalismo. Madrid: Akal.

Cabrera, M. (1997). La modernización económica. Los empresarios en la historia de España. Papeles de Economía Española, 73, 272-284.

- (2003). Empresarios y políticos en la democracia. De la crisis económica a las incertidumbres de la transición. Economía Industrial, 349-350, 51-62.

- (2011). Los Pactos de la Moncloa: acuerdos políticos frente a la crisis. Historia y Politica, 26, 81-110.

Cabrera, M. y Rey Reguillo, F. (1997). Corporativismo y articulación de intereses económicos en la España contemporánea. Working Paper, 396. Seminario de Historia Contemporánea. Madrid: Instituto Universitario Ortega y Gasset.

Cabrera, M. y Rey Reguillo, F. (2002). El poder de los empresarios. Política y economía en la España contemporánea (1875-2000). Madrid: Taurus.

98 Wright Mills (1987): 15.

99 Juliá (1997): 285. 
Calvo-Sotelo, L. (1990). Memoria viva de la transición. Barcelona: Plaza y Janés.

Caro, D. (2015). La reconstrucción del PSOE en la Andalucía Occidental: entre la memoria histórica y la renovación (1975-1982). Historia del Presente, 26, 11-26.

Castillo, P. del (1985). La financiación de partidos y candidatos en las democracias occidentales. Madrid: Centro de Investigaciones Sociológicas.

Cercas, J. (2009). Anatomía de un instante. Barcelona: Mondadori.

Círculo de Empresarios (2013). 35 años de contribución a la sociedad española, 1977-2012. Madrid: Círculo de Empresarios.

Collombat, B. y Servenay, D. (dirs.) (2014). Histoire secrète du patronat de 1945 à nos jours. París: La Découverte.

Crozier, M., Huntington, S. y Watanuki, J. (1975). The Crisis of Democracy: Report on the Governability of Democracies to the Trilateral Commission. Nueva York: Universidad de Nueva York.

Díaz-Varela, M. y Guindal, M. (1990). A la sombra del poder. Barcelona: Tibidabo.

Etxezarreta, M. (1991). La economía política del proceso de acumulación. En M. Etxezarreta (coord.). La reestructuración del capitalismo en España, 1970-1990 (pp. 31-94). Barcelona: Icaria.

Foucault, M. (2007). Nacimiento de la Biopolitica. Buenos Aires: Fondo de Cultura Económica.

Fuentes Quintana, E. (1989). Tres decenios de la economía española en perspectiva. En J. L. García Delgado (coord.). España, economía (pp. 1-75). Madrid: Espasa Calpe.

García Crespo, G. (2016). Enero de 1981: entre el «golpe de timón» y el golpe de Estado. Un documento revelador. Historia del Presente, 28, 157-171.

- (2019). El precio de Europa. Estrategias empresariales ante el Mercado Común y la Transición a la democracia en España. Granada: Comares.

García Delgado, J. L. y Serrano, J. M. (1990). De la primera crisis energética a las elecciones del 77: tiempo de incertidumbre. En J. L. García Delgado (dir.). Economía española de la transición y la democracia (pp. 3-22). Madrid: Centro de Investigaciones Sociológicas. Garrigues, J. (2006). Industrie, politique et vecteurs d'influence. En D. Barjot et al. (dirs.). Industrie et politique en Europe occidentale et aux Etats-Unis, $x i x^{e}-x x^{e}$ siècles (pp. 77-98). París: Universidad París-Sorbona.

Gattaz, Y. (1988). Les patrons reviennent. París: Laffont.

George, S. (2007). El pensamiento secuestrado. Barcelona: Icaria.

González Fernández, Á. (2007). El Consejo Nacional de Empresarios ante el proceso de reforma política. En R. Quirosa-Cheyrouze (coord.). Historia de la Transición en España (pp. 169-181). Madrid: Biblioteca Nueva.

(2010). Los empresarios ante los procesos democratizadores: las experiencias portuguesa y española. En E. Lemus, F. Rosas y R. Varela (coords.). El fin de las dictaduras ibéricas (1974-1978) (pp. 185-208). Sevilla: Centro de Estudios Andaluces.

_ (2015). «Una sociedad con libertades». La Confederación Española de Organizaciones Empresariales y la Constitución de 1978. Individu et nation [en línea], 6.

Guerra, A. (2005). Cuando el tiempo nos alcanza. Madrid: Espasa Calpe.

Harvey, D. (2007). Breve historia del neoliberalismo. Madrid: Akal. 
Hopkin, J. (1993). La desintegración de la Unión de Centro Democrático: una interpretación organizativa. Revista de Estudios Politicos, 81, 185-210.

- (1999). El partido de la Transición. Ascenso y caída de la UCD. Madrid: Acento.

Jáuregui, F. (1987). La derecha después de Fraga. Madrid: El País.

Juliá, S. (1997). Contra el reduccionismo. Papeles de Economía Española, 73, 285-288.

Linz, J. J. (1988). Política e intereses a lo largo de un siglo en España, 1880-1980. En M. Pérez Yruela y S. Giner (eds.). El corporatismo en España (pp. 67-123). Barcelona: Ariel.

Márquez, F. (2012). José María Cuevas o la aventura de la CEOE. Madrid: Cinca.

Milián, M. (2016). Els ponts trencats. Barcelona: Pòrtic.

Molinero, C. e Ysàs, P. (1998). Productores disciplinados y minorías subversivas. Madrid: Siglo xxI.

Montero, J. R. (1987). Los fracasos políticos y electorales de la derecha española: Alianza Popular, 1976-1986. Revista Española de Investigaciones Sociológicas, 39, 7-43. Disponible en: https://doi.org/10.2307/40183292.

Montero, J. R., Gunther, R. y Torcal, M. (1999). Legitimidad, descontento y desafección. El caso español. Estudios Públicos, 74, 107-149.

Morán, G. (2009). Adolfo Suárez. Ambición y destino. Barcelona: Debate.

Oliet, A. (2000). La concertación social en la transición: la génesis de un modelo de intercambio. Espacio, Tiempo y Forma. Serie V, Historia Contemporánea, 13, 441-480.

Pérez Díaz, V. (1987). El retorno de la sociedad civil. Madrid: Instituto de Estudios Económicos.

Pérez Ledesma, M. (1997). Empresarios, políticos e historiadores. Papeles de Economía Española, 73, 289-293.

Pérez Vilariño, J. (1987). Las primeras elecciones al Parlamento gallego. En J. Pérez Vilariño (ed.). Comportamiento electoral y nacionalismo en Cataluña, Galicia y País Vasco (pp. 57-89). Santiago: Universidad de Santiago de Compostela.

Phillips-Fein, K. (2009). Invisible hands: the Businessmen's crusade against the New Deal. Nueva York: Norton.

Powell, Ch. (2001). España en democracia, 1975-2000. Barcelona: Plaza y Janés.

Pro, J. (1997). De empresarios modernos y malvados patronos en la Espańa del siglo xx. Papeles de Economía Española, 73, 294-304.

— (2007). Introducción: poderes privados y recursos públicos. Ayer, 66, 11-26.

Rojo, L. Á. (1987). La crisis de la economía española, I973-1984. En J. Nadal, A. Carreras, C. Sudrià (comps.). La economía española en el siglo XX. Una perspectiva histórica (pp. 190-200). Barcelona: Ariel.

Ruíz-Rico, G. (2015). El control sobre la financiación de los partidos políticos: un desafío permanente para el legislador. Teoría y Realidad Constitucional, 35, 281-308. Disponible en: https://doi.org/10.5944/trc.35.2015.14920.

San Martín, J. I. (2006). Apuntes de un condenado por el 23-F. Madrid: Espasa.

Toboso. P. (2007). Empresarios y política en la dictadura de Franco. Ayer, 66, 143-173.

Trullen, J. (1993). Fundamentos económicos de la transición política española. Madrid: Ministerio de Trabajo y Seguridad Social.

Tunón de Lara, M. (1967). Historia y realidad del poder. Madrid: Cuadernos para el Diálogo. Wright Mills, C. (1987). La élite del poder. México: Fondo de Cultura Económica. 